\title{
The pulmonary blood volume variation is higher in patients with heart failure compared to healthy controls
}

\author{
Mikael Kanski ${ }^{*}$, Martin Ugander ${ }^{2}$, Rasmus Borgquist ${ }^{3}$, Håkan Arheden $^{1}$ \\ From 17th Annual SCMR Scientific Sessions \\ New Orleans, LA, USA. 16-19 January 2014
}

\section{Background}

In left ventricular heart failure, blood will congest backwards to the pulmonary circulation and result in an increased pulmonary vascular resistance. If the increase in pressure result in impaired gas exchange due to pulmonary oedema, the pulmonary blood will redistribute to better ventilated areas in order to maintain adequate gas exchange[1]. This might affect the pulsatility of the pulmonary blood flow which can be quantified by measuring the pulmonary blood volume variation (PBVV)[2]. Therefore, the aim of this study was to investigate if PBVV in patients with heart failure differed from healthy controls.

\section{Methods}

Fifteen patients with heart failure and 10 healthy volunteers underwent cardiac MRI at 1.5T. Flow measurements were acquired in the pulmonary trunk and all pulmonary veins. The PBVV was calculated by integrating the flow in all vessels leading to and from the pulmonary circulation. The PBVV was indexed to right ventricular stroke volume (PBVV/SV). Patients underwent a 6-minute walk test $(6 \mathrm{MWT})$ as an independent measure of functional capacity.

\section{Results}

Left ventricular ejection fraction (LVEF) in patients with heart failure and healthy controls were $27 \pm 6$ and $60 \pm$ $3 \%$, respectively $(\mathrm{p}<0.001)$. Patients had a significantly higher PBVV/SV compared to controls (58 $\pm 12 \%$ vs $40 \pm$ $5 \%, \mathrm{p}<0.001$, Figure 1), 3/15 (20\%) patients had PBVV/ $\mathrm{SV}$ values within the range of healthy controls. In patients, there was no relationship between PBVV/SV and the
LVEF ( $\mathrm{r} 2=0.13, \mathrm{p}=0.18$ ), atrioventricular plane displacement (AVPD, $\mathrm{r} 2=0.17, \mathrm{p}=0.12$ ), or 6 -minutes walk test (6MWT, $\mathrm{n}=8, \mathrm{r} 2=0.00, \mathrm{p}=0.90$ ).

\section{Conclusions}

Patients with heart failure had a higher PBVV/SV compared to healthy controls. This can be explained by a pulmonary circulatory response, either active or passive, to the failing left ventricle. However, the lack of correlation

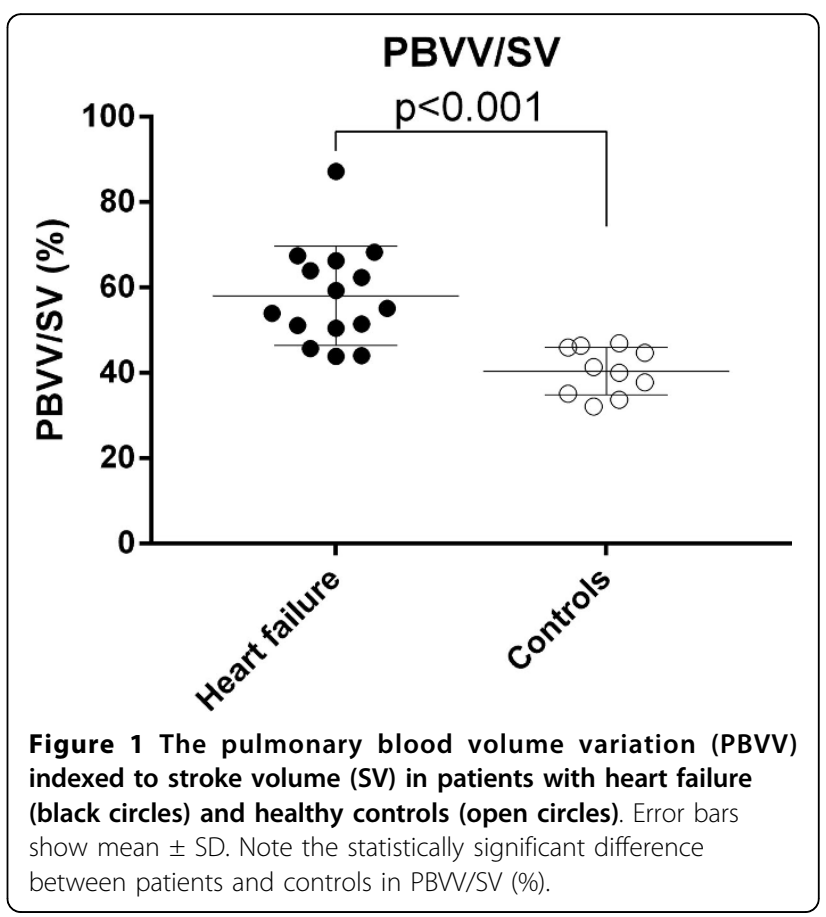


between PBVV/SV and LVEF, AVPD, or 6MWT suggests an active process in order to maintain an adequate gas exchange in the lungs. Therefore, we propose that PBVV/ $\mathrm{SV}$ may be a measure of the pulmonary circulatory involvement caused by heart failure.

\section{Funding}

Swedish Research Council, Swedish Heart and Lung Foundation, Medical Faculty at Lund University, Region of Scania.

\section{Authors' details}

'Department of Clinical Physiology, Lund University and Lund University Hospital, Lund, Lund, Sweden. ${ }^{2}$ Department of Clinical Physiology, Karolinska Institutet and Karolinska University Hospital, Stockholm, Sweden.

${ }^{3}$ Department of Cardiology, Lund University and Lund University Hospital,

Lund, Lund, Sweden.

Published: 16 January 2014

\section{References}

1. de G, Lee J: Regulation of the pulmonary circulation. Br Heart J 1971, 33(Suppl):15-26.

2. Ugander $M$, et al: Pulmonary Blood Volume Variation Decreases after Myocardial Infarction in Pigs: A Quantitative and Noninvasive MR Imaging Measure of Heart Failure. Radiology 2010, 256(2):415-23.

\section{Submit your next manuscript to BioMed Central} and take full advantage of:

- Convenient online submission

- Thorough peer review

- No space constraints or color figure charges

- Immediate publication on acceptance

- Inclusion in PubMed, CAS, Scopus and Google Scholar

- Research which is freely available for redistribution

Submit your manuscript at www.biomedcentral.com/submit 